\title{
Millenials' Employer Brand Perception in a German Retail Context
}

\author{
Krummel Daniel ${ }^{1}$, Siegfried Patrick ${ }^{2}$ (), Michel Alex ${ }^{3}$ \\ ${ }^{1}$ Business Administration, Baden-Wuerttemberg Cooperative State University (DHBW), Mannheim, Germany \\ ${ }^{2}$ International Management, Logistics \& Supply Chain Management, International School of Management, Frankfurt, Germany \\ ${ }^{3}$ International Management, Logistics \& Operations Department, International School of Management, Frankfurt, Germany \\ Email: daniel.krummel@yahoo.de
}

How to cite this paper: Daniel, K., Patrick, S., \& Alex, M. (2020). Millenials' Employer Brand Perception in a German Retail Context. Journal of Human Resource and Sustainability Studies, 8, 396-418. https://doi.org/10.4236/jhrss.2020.84023

Received: November 5, 2020

Accepted: December 19, 2020

Published: December 22, 2020

Copyright (c) 2020 by author(s) and Scientific Research Publishing Inc. This work is licensed under the Creative Commons Attribution International License (CC BY 4.0).

http://creativecommons.org/licenses/by/4.0/

(c) (i) Open Access

\begin{abstract}
Since tangible assets of companies are becoming increasingly insignificant, emphasis should rather be placed on human capital as an essential source of competitive edge. This paper, accordingly, pursues the purpose to shed light on the major demands that the Millenials place on their prospective employers. In consequence, the work aims to identify attractiveness factors that German retailers should particularly promote in order to succeed in the war for talents and attract the most promising candidates among the German Gen Y. This work is based on a mixed-methods approach. First, interviews with German retail experts as well as generational keynote speakers were conducted in order to obtain a deep understanding and assessment of the German retail landscape from a professional perspective. The insights gained were subsequently used to design a questionnaire, which distribution led to a final sample of 216 useable responses by Millenials. Furthermore, the data obtained by interviewing experts and the survey was subsequently compared in order to evaluate to what extent the expectations of the Millenials correspond to the experts' assessment. This study reveals Millenials to be driven by the need for growth, such as wide offers of development opportunities or scope for decision when choosing an employer. Among the relatedness needs, a harmonious working environment is particularly important, whereas a weekend off ranks first among the existential needs. Moreover, male Millenials consider Media Markt being the most popular employer in the German retail sector, while $\mathrm{dm}$ is preferred from a female perspective. Overall, employers of the German retail sector provide the majority of factors required by the Millenials, yet are only considered the 4th most popular industry behind the automotive, IT, art and entertainment industries. Our findings provide valuable practical implications as the research results might serve companies to build up a target group specific employer brand. Marketing strategies can be aligned with the identified attractiveness factors to efficiently and cost-effectively at-
\end{abstract}


tract and bind Millenials to the company. Customized recruiting campaigns enhance the appeal as well as the attractiveness of an employer driving the likelihood of obtaining the strived status: Employer of Choice. To the best of the author's knowledge, no study has yet dealt specifically with the attractiveness factors demanded by the Millenials in the context of the German retail sector as well as their most aspired employers in this industry. Furthermore, the attractiveness factors identified in the literature were embedded in Aldefer's ERG theory. This work also offers a bilateral perspective through the widely conducted survey carried out among Millenials, which was additionally expanded through the lens of experts.

\section{Keywords}

Employer Branding, Generation Y, Millenials, Employer Attractiveness Factors, Retailing

\section{Introduction}

"Attracting potential candidates is important to the recruitment process, which is key to organizations because human capital is crucial for competitive advantage."

(Eger et al., 2019: p. 520)

The advancing complexity and dynamics of the German economy increase the demand for highly qualified employees. Demographic developments in particular are driving the competition for young talented professionals (Geighardt-Knollmann, 2011). It is therefore crucial for employers to know the selection criteria of prospective employees and to consider them when recruiting, notably since the brand and the human capital of companies constitute the principal sources of competitive edge (Stotz \& Wedel, 2009, 2013; Sharma \& Prasad, 2018). Various research findings show that values and attitudes towards the workplace differ by generation, age and gender (e.g. Sengupta et al., 2015; Tanwar \& Prasad, 2016; Bartosik-Purgat \& Jankowska, 2017).

In 2018, around 15.84 million Millenials contributed to the total German population (Destatis, 2019), which, with 46.18 million people in employment (Destatis, 2020), accounts for a proportion of $34.3 \%$. This fact additionally accentuates the importance of this cohort for the German economy including the retail sector. Beyond that, despite 3.08 million current employees (HDE, 2019), many retailers encounter difficulties in filling vacant positions with skilled professionals (Ifo, 2018). A major aim of employers must therefore be the identification of the attractiveness factors favoured by Millenials in order to create an effective employer brand allowing for a successful positioning in the competitive landscape (Ruthus, 2014).

This study pursues a threefold objective: First, to identify preferred attractiveness dimensions of an employer brand among German students; secondly, this paper intends to shed light on the attractiveness perception of the German 
retail trade from an employee angle by Generation Y; thirdly, explore whether there are any gender-specific differences with respect to the desired employers in the German retail trade.

In order to reach the defined objectives, a detailed literature review was carried out in the upcoming chapter serving as a basis for subsequent data collection and empirical research.

\section{Literature Review}

In order to identify previous studies concerning employer branding in a German context, an extensive literature review was performed using various databases. Terms such as "employer branding", "employer brand", "employer attractiveness factors" and "Millenials' employer preferences" were employed as search parameters. The investigation revealed a lack of employer branding studies with specific reference to the German retail sector. Thus, the international research community has not yet embedded employer branding in a retail sector environment, necessitating this study's approach.

\subsection{Generation $Y$}

Various research results show that values and attitudes regarding the workplace differ by generation, age and gender (Kim et al., 2009; Cisik, 2015). The generation concept in particular has been discussed internationally in recent years (Wong et al., 2008). A generation is an identifiable group that shares birth cohorts and important political as well as social events in the formative developmental phase in childhood and adolescence (Kupperschmidt, 2000).

Yet, a precise definition of the individual generations is intricate, as cultural factors also have a considerable influence. Accordingly, research on generational differences regarding work values is still in its infancy (Ruthus, 2014). Nevertheless, the scarce systematic studies on generational disparities in the workplace indicate that there are varying perceptions and aspirations of employees across different age groups (Twenge et al., 2010). Frequently, a common distinction is made according to the demands of the workplace, employees' needs and behavioral characteristics (Holste, 2012). This work centers its research efforts on the Generation Y (allias Millenials) as alluded to in Figure 1.
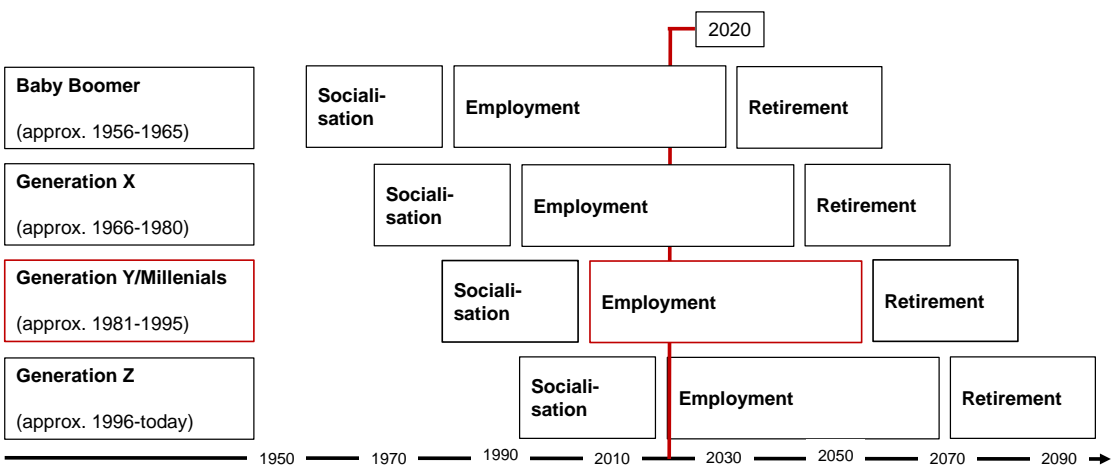

Figure 1. Generations on the German labour market, adapted from Klaffke 2014: p. 12. 
The representatives of this generation were born in the approximate period of 1981 and 2000, currently being between the ages of 20 and 39 and thus form the youngest currently employed generation (Ruthus, 2013). Yet, there is a certain ambiguity in the literature as regards the exact period of demarcation. In any case, this generation represents the most important future professionals and managers as currently accounting for the bulk of the German workforce. The design of the employer branding processes should thus be adapted to them particularly (Künzel, 2013). The term "Y" can be explained from two points of view. On the one hand, Generation Y (pronounced "why?"), for example, refers to the predecessor generation $\mathrm{X}$, but it also represents the generation that questions everything, such as values and existing structures (Köcher et al., 2015). This generation has grown up in a time of relative political and economic stability, therefore beyond the sphere of world wars, which does not apply to their prior generations for the most part. Consequently, a positive anticipation of the future, strong self-confidence, solution orientation and functionality are among their characteristics. As a result, Holste (2012) in line with Parment (2013) attest the Generation $Y$ to enter the labour market with completely altered values, aspirations and confidence causing a discrepancy between pressure of expectation, urge for freedom, identification and joy.

\subsection{Employer Brand}

The concept of employer branding was first coined by Ambler and Barrow (1996), who defined the term as "the package of functional, economic and psychological benefits provided by employment, and identified with the employing company" (p. 187). Yet, there is no unified definition to date (Moroko \& Uncles, 2008; Theurer et al., 2018).

Due to the increasing shortage of skilled workers in knowledge and service industries (Eger et al., 2019), the employer brand is increasingly recognised among various fields of research as an effective instrument for attracting (Graham \& Cascio, 2018) prospective and retaining present employees (Alniacik et al., 2014).

The main objective of an employer brand is to achieve the most pronounced preference possible in the respective target group. This means that from the perspective of existing and potential employees, the employer is the first to be chosen and thus being an "Employer of Choice" (Stotz \& Wedel, 2009, 2013). Accordingly, to stand out from the mass of anonymity, companies are required to establish a unique employer brand, similar to a Unique Selling Proposition (USP). This allows the company to differentiate itself as an employer from the competition and to appear as a unique workplace (Walter \& Kremmel, 2016). Beyond that, the employer brand serves as identification means. The feeling of belongingness to the company, i.e. the coverage of one's own values with those of the employer, leads to increased employee satisfaction. Consequently, satisfied employees are more motivated and willing to perform (Kanfer et al., 2017), which in turn leads to increased customer satisfaction. Ultimately, satisfied cus- 
tomers are loyal, contributing to a greater extent to the success of the company. Especially in the retail trade, as direct intersection to the end consumer, employees' motivation is positively correlated with the success of the retailer (Stotz und Wedel, 2009, 2013).

Despite the significance of the topic, scientific discussions about it are still sparse (Christiaans, 2013). Besides, EB research mainly focuses on developed countries (Zhu et al., 2014; Lee et al., 2018), thus some papers have also placed EB in a German context (e.g. Baum \& Kabst, 2013; Holtbrügge \& Kreppel, 2015; Sommer et al., 2017; Steckl et al., 2019). Yet, a broad identification of employer attractiveness factors of Gen Y in Germany, in particular in a retail context, is still missing.

Moreover, the employer brand has a significant impact on corporate culture and image, thereby affecting perceived employer attractiveness, defined by Berthon et al. (2005: p. 156) "as the envisioned benefits that a potential employee sees in working for a specific organisation". Consequently, if an employer has distinguished itself as an Employer of Choice, the zenith of employer attractiveness is reached (Wolf, 2014). The fact that employees' sense of attractiveness depends on the extent to which the desires of employees are met makes them particularly relevant to the company's management (Wolf, 2014).

Last year, in none of the prominent employer rankings, such as Great Place to Work (2019), Kununu Ranking and Glassdoor Award, were any retailers listed in the German Top 20 (FAZIT, 2019). Merely the Trendence student barometer, with IKEA in 18th place, ranks a retailer among the best (Trendence, 2019). This allows the conclusion that the retail trade is not considered particularly attractive by the Millenials which rather prefer automobile manufacturers and IT concerns, occupying the top positions.

\subsection{Factors Affecting Employer Attractiveness (ERP-Theory)}

The perceived attractiveness of employers is multidimensional and comprises both job and organizational aspects (Ambler \& Barrow, 1996). The employer branding literature provides a wide range of attributes that have been assigned to different main categories by various studies in this context. For instance, Ambler and Barrow (1996) distinguished three main dimensions of attractiveness factors (see Table 1). Berthon et al. (2005) later refined and extended their categorization by determining 25 employer attractiveness attributes that have been divided into 5 distinct categories.

Table 1. Comparative employer attractiveness dimensions/studies.

\begin{tabular}{ccc}
\hline Alderfer (1969) & Ambler \& Barrow (1996) & Berthon et al. (2005) \\
\hline Growth needs & Functional & Development value Application value \\
Relatedness needs & Psychological & Social value Interest value \\
Existence needs & Economic & Economic value \\
\hline
\end{tabular}


In the study at hand, a categorization of employee needs respectively employer attractiveness factors was carried out employing the ERG (Existence, Relatedness and Growth) theory established by Alderfer (1969), which constitutes a further development of Maslow's hierarchy of needs theory. His approach "assumes that a human being has three core needs that he strives to meet" (Alderfer, 1969: p. 145), which comprise the maintenance of material existence needs, interpersonal relatedness with important other people, and seeking opportunities for personal development and growth (Ibid.). Below, a definition for each of the three ERG dimensions are given:

- "Existence needs include all the various forms of material and physiological desires" (e.g. hunger and thirst are considered deficiencies in existence needs; Alderfer, 1969: p. 145)

- "Relatedness needs include all the needs which involve relationships with significant other people" (e.g. family members or friends; Alderfer, 1969: p. 145)

- "Growth needs include all the needs which involve a person making creative or productive effects on himself and the environment" (Alderfer, 1969, p. 145)

Based on Ambler \& Barrow (1996), Berthon et al. (2005) and previous empirical surveys of the Embrace (2015) study "Karriere trifft Sinn", Universum Communications "Young Professionals" Study (2013) as well as the Shell Youth Study 2019 (Shell, 2019) attractiveness factors were identified and subsequently assigned to corresponding ERG categories (see Table 1).

The employer selection criteria, as illustrated in Table 2, found in the above-mentioned studies were found to be best assigned to the ERG categories in their scope rather than to the dimensions proposed by Alderfer (1969) and Ambler and Barrow (1996). In addition, the use of a theory based on Maslow's pyramid of needs was considered adequate for determining factors of need in terms of employer selection. It was therefore drawn on the ERG theory. Besides, it has proven more successful in the working environment than the one developed

Table 2. Attractiveness factors of generation Y (ERG theory), conceptualised employer attractiveness model.

\begin{tabular}{ccc}
\hline Existence Needs & Relatedness Needs & Growth Needs \\
(High) compensation & Corporate culture & Good chances of employment \\
Job security & $\begin{array}{c}\text { Harmonious working } \\
\text { environment }\end{array}$ & Development opportunities \\
Work-Life-Balance & Employer reputation & Meaningful work \\
Proximity to the workplace & Esteem & Scope for decisions \\
Family friendliness & Flexibility & Feedback culture \\
Free weekends & Corporate Social & Responsibility (CSR) \\
Recognition of performance & Corporate transparency & Challenging work \\
\hline
\end{tabular}


by Maslow (e.g. Hackman \& Lawler, 1971; Frank et al., 2004; Lindgren \& Skarpet, 2008; Tepper et al., 2018) as it does not require the satisfaction of lower-level needs as prerequisite to allow for higher-order needs (Alderfer, 1969). There is accordingly no hierarchical order, so that all needs are considered equally relevant (Ibid.).

Beyond that, it was refrained from exactly copying attributes and dimensions established by Berthon et al. (2005) since their work refers across all industries and, with Australian students, to an Anglo-Saxon labour market or liberal market economy, to which the German job market cannot be assigned as being a coordinated market economy (Hall \& Soskice, 2001) Fundamental differences can thus be assumed in this case. On the basis of the expert interviews, the pre-selection was reduced and factors were identified that are of immediate relevance to employers in the German retail sector.

In a German context, Steckl et al. (2019) surveyed 383 students $\left(\mathrm{N}_{\text {female }}=191\right.$, $\mathrm{N}_{\text {male }}=192$ ) and found job security (95\%), harmonious working environment $(88 \%)$, social support within the team $(86 \%)$, high compensation $(85 \%)$ and recognition (83\%) being the most important factors affecting the employer selection.

Beyond that, Sommer et al. (2017) proofed that an organization with innovative product portfolios and innovative cultures is likely to attract prospective employees. Both were evidenced at significance level $p<0.01$. However, the extent of influence is dependent on the individual's level of innovativeness. The company's location (今̂proximity to the workplace) and reputation were also found to be highly significant, albeit slightly weaker than the two others. Overall, employer branding was found an effective tool to enhance employer perceptions and to attract new employees (Sommer, 2017).

Baum and Kabst (2013) conducted a cross-cultural study including 1626 students which yielded that working atmosphere $(\beta=0.30, p<0.001)$ as well as career and development opportunities $(\beta=0.23, p<0.001)$ are the main attractiveness drivers within the German labor market. Bahner and Eisele (2004) reach a quite similar conclusion whereas compensation comes second before career advancement. However, among German business administration students Franke (2000) proofed the latter to be the most important determinant of employer selection.

A further survey $\left(\mathrm{N}_{\text {total }}=726, \mathrm{~N}_{\text {Millenias }}=705\right)$ revealed that in Germany, compensation, job security and good work-life-balance in particular play a crucial role in the perceived attractiveness of employers (Holtbrügge \& Kreppel, 2015). Nevertheless, this perception differs across the various industries (Ibid.).

The thorough analysis of the literature allows the following hypothesis:

Hypothesis 1: The retail sector is perceived as merely moderately attractive from a Millenials perspective.

Hypothesis 2: The retail sector offers only a limited array of relevant attractiveness factors.

The following section roughly outlines the employed methodological approach. 


\section{Methodology}

\subsection{Research Design and Strategy}

Following the recommendations of Mahotra (2010), this paper adopts a mixed methods approach, whereby the quantitative research is extended by a qualitative component aiming at a more comprehensive understanding of the topic (Flick, 2014). The results of the interviews were contrasted with those obtained from the survey. Since employers can only win over and retain employees by means of an appealing attractiveness portfolio and desired factors-offer, it seemed a logical step to compare the assessment of employers resp. experts with the expectations of employees resp. Millenials.

\subsubsection{Qualitative Research}

The qualitative primary data was collected by means of semi-structured interviews with experts from the German retail sector as well as experts of Employer Branding in retailing as illustrated by Table 3.

These interviews were conducted in the preliminary stage of the survey among Millenials in order to be able to implement improvement potentials with regard to an adequate formulation of questions. They also functioned as a supplementary perspective of employers, subsequently compared with the expectations of the Millenials. The conversations took place in the period February to April 2020 and were performed by phone and via Skype. In terms of data analysis, the interviews were recorded and subsequently transcribed verbatim (Graue, 2015). The transcription was necessary to maintain the quality of the data. The evaluation was carried out using NVivo to ensure a comparable overview using the same coding method for all transcripts.

\subsubsection{Quantitative Research}

A quantitative approach was applied in order to enable the generalizability of the results (Malhotra, 2010).

The questionnaire for the survey among the Millenials consisted of four sections. The first served to introduce the researcher as well as the research project and to welcome the participants. The second section, served to find out which industries the Millenials prefer. The third section, the questionnaire main body, covered questions concerning the attractiveness factors associated with the individual

Table 3. Overview of industry experts interviewed.

\begin{tabular}{cccc}
\hline Expert anonymised & Expert & Position & Industry \\
\hline A & Amy Lynch & Self-employed Keynote Speaker & - \\
B & Felix Plötz & $\begin{array}{c}\text { Self-employed Keynote Speaker } \\
\text { and SPIEGEL bestselling author }\end{array}$ & - \\
C & Vanessa Zielonka & $\begin{array}{c}\text { Consultant and Deputy } \\
\text { Head of Academy (DEBA) }\end{array}$ & Consultancy \\
D & Melanie Litterst & Recruitment (dm) & Retail trade \\
E & Christian Körner & Recruitment (BAUHAUS) & Retail trade
\end{tabular}


ERG dimensions. Here, the Millenials were supposed to indicate the degree of their agreement with the individual factors. The fourth and final section included questions regarding the demographics of the respondents on their gender and age. In order to generally provide its reliability and validity, the questionnaire was adjusted in terms of accuracy after consultation with the supervisor prior to its distribution. Besides, the questions were derived from the factors of previous studies.

\subsection{Sample and Data Collection}

In terms of quantitative research, a sample comprised of $\mathrm{N}=216$ German students (120 female, 96 male), ranged 19 to 25 years of age, from a school in Stuttgart was surveyed in a period spanned 09.04. to 27.04.2018. The author opted for Millenials, as these are currently the main target group of recruitment efforts (Berthon et al., 2005). Furthermore, they represent the lion's share of current job seekers and are therefore particularly concerned with aspects which they consider important for an employer (Andreassen \& Lanseng, 2010). In total, 232 questionnaires were distributed, of which 216 were returned properly completed, securing a $93.10 \%$ response rate. A standardized questionnaire consisting of nine closed and two open questions was used to ensure maximum comparability and validity. The closed questions were responded on a five-point Likert scale, chosen to avoid imposing on the respondents in either direction. The tendency towards the middle was additionally tolerated due to the freedom of choice.

The remaining open questions were intended to provide new perspectives that have not been taken into account when the questionnaire was prepared.

In order to assess whether the empirical results correspond with the estimation and expectations of employer branding experts, five semi-structured interviews were additionally conducted. Besides, this also allowed to gain a more profound insight into the subject matter (Winter, 2000).

\subsection{Data Analysis}

Initially, the questionnaires were manually captured and divided subsequently into male and female subjects. The results were then recorded using Microsoft Excel. This enabled the author to present the results graphically and well arranged. In order to facilitate a comparison, the numerical values from the survey are depicted as percentages. A specific consideration of the individual age cohorts is not necessary, as the participants are considered as part of Generation $\mathrm{Y}$ and are thus part of a homogeneous mass. This mass was already defined idem.

The findings from a survey of 216 German students on employer attractiveness factors are presented hereafter.

\section{Findings and Discussion}

\subsection{The Most Attractive Industries from a Gen Y Perspective}

The comparison with previous studies provides partial agreements as well as 
unexpected differences.

In terms of the third research question, the findings of a cross-gender assessment substantiate, in accordance with the most famous employer rankings, that the automotive industry is considered the most popular sector among $56 \%$ of the respondents, closely trailed by the IT sector (50\%). The retail sector already ranks fourth, hold being attractive by $43 \%$ of the participants, and is thus still within the Top 5 of the most popular sectors from the perspective of the Millenials from a predefined total selection of ten industries.

The results show that the art and entertainment industry is most popular among $70 \%$ of the female participants. Here, retail trade ranks second and is considered appealing by almost every second respondent (47\%). Subsequently, the automotive industry follows as being considered attractive by $40 \%$ and the IT sector by $37 \%$. Noteworthy, since the survey was carried out at a vocational school for design and art, the results may be slightly biased. With $76 \%$ approval, the automotive industry is the undisputed number one of the most popular industries from a male perspective. This reflects the latest research findings from a study carried out by Stern and Statista, revealing four automotive companies (e.g. Daimler, BMW) being among the Top 10 most popular employers in Germany in 2019 (Wolter, 2020).

Surprisingly, these results do not coincide with those of Holtbrügge and Kreppel (2015), which found that neither age nor gender affects the preferences for certain employer characteristics among German Millenials. affiliation.

\subsection{Millenials' Attractivity Perception of German Retailing}

With regard to the second research question, to find out which general characteristics the Millenials ascribe to the retail sector, seven attributes, as shown in Figure 2, ought to be used to make their assessment of retail. Since the ranking of the following results differed only negligibly between female and male respondents, no gender-specific analysis is made henceforth. Accordingly, the results are reported on a cumulative basis.

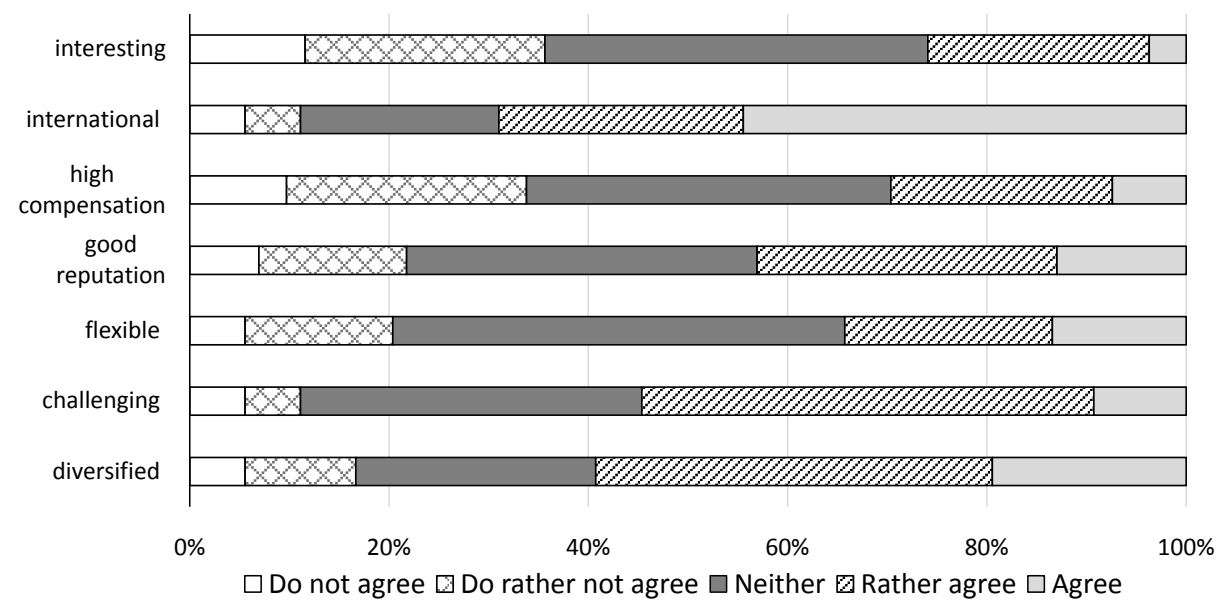

Figure 2. Characteristics of retail from the respondents' perspective. 
The overall picture provides the following results: Most of the respondents (69\%) perceive the retail industry as internationally oriented, which is probably due to the extensive international branch network of many famous retailers. The second rank among the ascribed characteristics is diversified, confirmed by $59 \%$, which is closely followed by the positive attribution of the properties challenging (55\%) and reputation of the retail trade (42\%). However, this reputation is disputed by $22 \%$ of the participants, nearly one in four. With regard to interesting activities (36\%) and high compensation (34\%), the majority assume these characteristics being rather not or not applicable at all. Besides, a high level of impartiality is also evident in this respect. Thus, it can be conclusively stated, that the respondents consider the retail sector to be highly internationally oriented, diversified and additionally demanding. Yet, tasks in retail are also perceived as monotonous and poorly paid.

By means of an open question the probands were able to express additional comments on their expectations regarding employment in the retail trade. Hereinafter are a few comments that the author has deemed relevant:

"Honestly, not much or very little demanding."

This commentary contradicts the totality of the survey results, but also shows the contrasting nature of perceptions among individual Millenials.

"Clean out the warehouse, work the checkstand and order new goods."

"Work on the sales floor, shift work and few weekends off."

"Varied work, but also requires a lot of physical labor."

These commentaries allow the conclusion that working in retail is almost exclusively associated with activities on the sales floor or in the store rather than headquarters which accordingly completely escapes the expectation horizon as working space. The notion of undemanding work becomes once more evident. However, variety is additionally confirmed.

What additional services do Millenials expect to be offered by retail trade employers?

With $68 \%$ ("agree" and "rather agree"), most of the survey participants expect a wide range of parking facilities, presumably due to the offer by branches (see Figure 3). The parking spaces on offer thus have the highest weighting shared with the expectation of high-quality products as being on a par with the parking facilities. Here, however, only $24 \%$ "agree". Hygiene and cleanliness occupy the third place (57\%). Hygiene and cleanliness come in third place (57\%). Taken more or less equally, the remainder is rated as follows: Proximity to the home (30\% "rather agree" and "agree"), quiet working atmosphere (28\% "rather agree" and "agree"), modern workplace (28\% "rather agree" and "agree") and participation in shaping the working environment (24\% "rather agree" and "agree").

The following characteristics also bear similar weighting: company events and excursions (17\% "rather agree" and "agree"), flexi-time, home office and sports possibilities (15\% "rather agree" and "agree" respectively). But which characteristics are not associated with retail jobs? For instance, $60 \%$ of those surveyed consider sports opportunities to be not applicable. A further 52\% largely rule out 


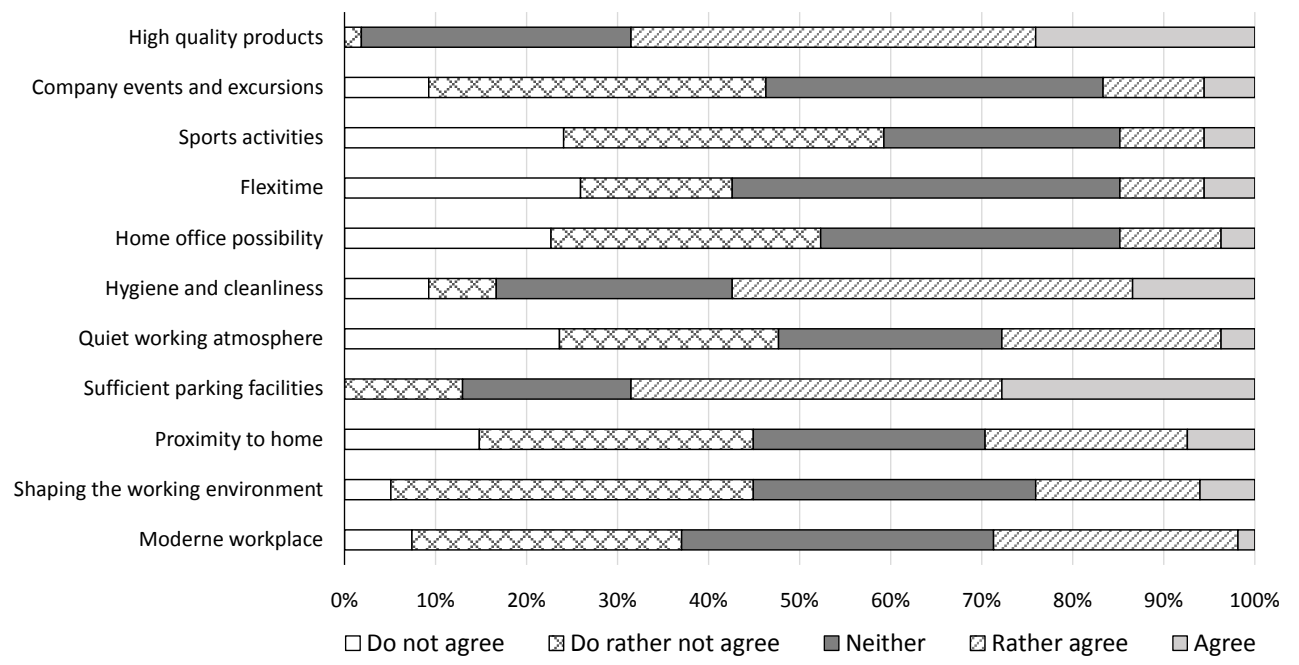

Figure 3. Additional incentives of retail employers anticipated by Millenials.

home office facilities in retail. Even a quiet working atmosphere is rated by $48 \%$ as "rather not applicable" or "not applicable". Furthermore, rated as "rather not" or "not applicable" are: Company events and excursions to $46 \%$, proximity to the home and participation in shaping the working environment to $44 \%$ each, flexi-time to $42 \%$, hygiene and cleanliness to $17 \%$ and sufficient parking facilities form the final result with $13 \%$ ("rather not applicable").

It is conspicuous that the most pronounced expectations, such as high-quality products and sufficient parking facilities, are more in line with a customer's point of view, and actual employee incentives such as flexi-time or home office only follow at the bottom of the list. It can therefore be concluded that the retail trade is perceived as an employer to a limited extent merely and, if it is, that jobs in the headquarters or office occupations are unconsidered, rather associated with branch and sales area activities.

\subsection{The Most Popular Retailing Employers among German Millenials}

In order to determine the most popular employers in the German retail sector from the perspective of the Millenials, the probands were asked to choose their preference from a selection of 21 retailers, as presented in Figure 4.

Additional employers, also beyond the retail industry, that were not included in the list $(\mathrm{N}=21)$ could additionally be added as "others". Accordingly, only $77.5 \%$ of the female participants gave their vote to one of the predefined employers. Among the male respondents, the value was significantly higher at $90.6 \%$, indicating a more selective behaviour of female in contrast to male concerning their choice of employer in the retail trade. Furthermore, from a male perspective, Media Markt with approx. 20\% and Saturn with $16 \%$ are by far perceived as most attractive employers in retail. $\mathrm{dm}$ and Decathlon follow in third place with 9\% each. The male respondents cited SAP, Google, start-ups in general, GameStop, GQ and Daimler as other possible employer preferences. 


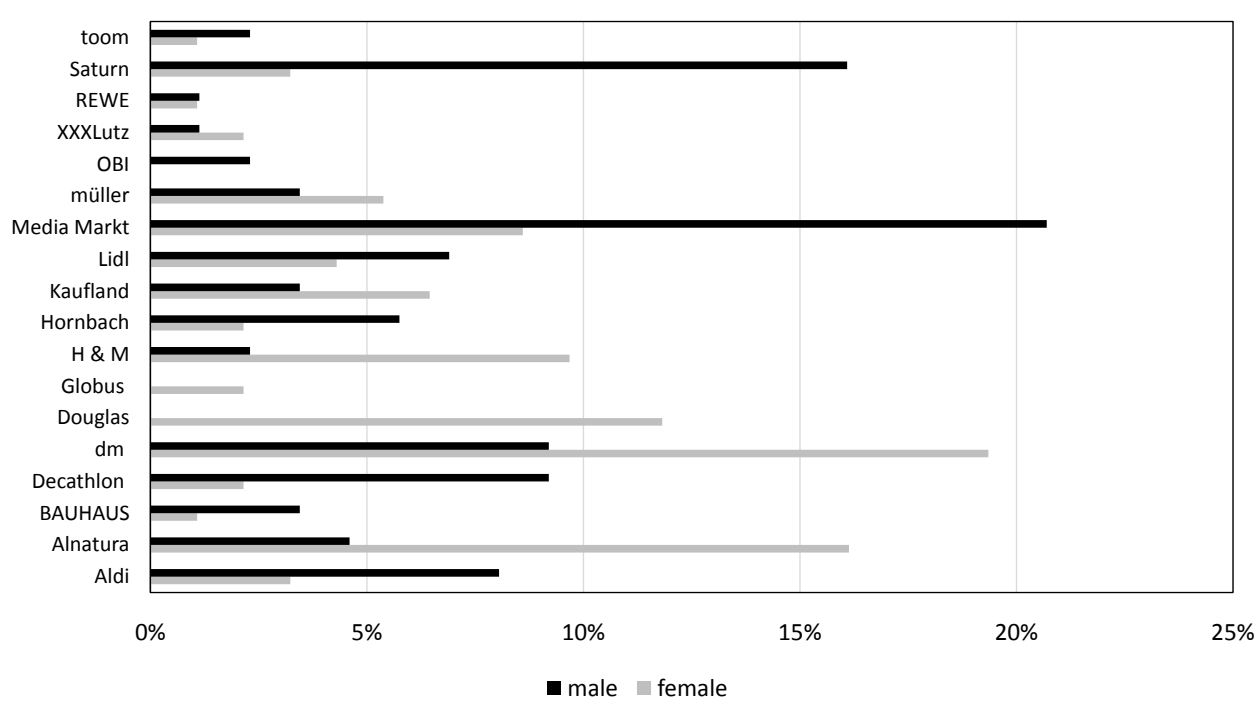

Figure 4. Millenials' retail employer popularity ranking.

dm (19\%), Alnatura (16\%) and Douglas (12\%) are the most attractive employers from a female perspective. Surprisingly, $\mathrm{dm}$ is already ranked third among male preferences with $9 \%$ as the general perception is that the drugstore staff consists exclusively of women. Furthermore, the majority of the product range at $\mathrm{dm}$ is geared to female demand. Consequently, $\mathrm{dm}$ is unconsciously perceived as a strong employer brand, without, however, making any active efforts to establish one (dm Interview). Calzedonia, Forever 21, Promod, Facebook, Instagram, Prada, Lufthansa and sneaker shops such as Foodlocker or snipes were named by the women as other desired employers.

The gender-specific naming of additional employers suggests the reflection of social stigmatisation, as women show an interest in fashion and cosmetics companies, whereas men tend to have an affinity for new technical equipment, videogames and sports goods. Interestingly, $\mathrm{dm}$ is already in third place among male preferences, although the range of products on offer there does not suggest this at first glance. The strength of the drugstore market is that the communicated values are also supported from within the company, attests Expert D. That gets around and gives accordingly a good reputation.

\subsection{Which Attractiveness Factors Are Decisive for Millenials in Selecting an Employer}

The following section reveals the relevance of particular attractiveness factors of the respective ERG categories rendering employers desired from a Millenials' perspective.

\section{Existence Needs}

Figure 5 beneath illustrates the factors of the choice of employer, classified by existential needs.

As shown in the figure above, a free weekend is perceived by $48 \%$ as "very important" and by $33 \%$ as "important" when choosing an employer. This factor 


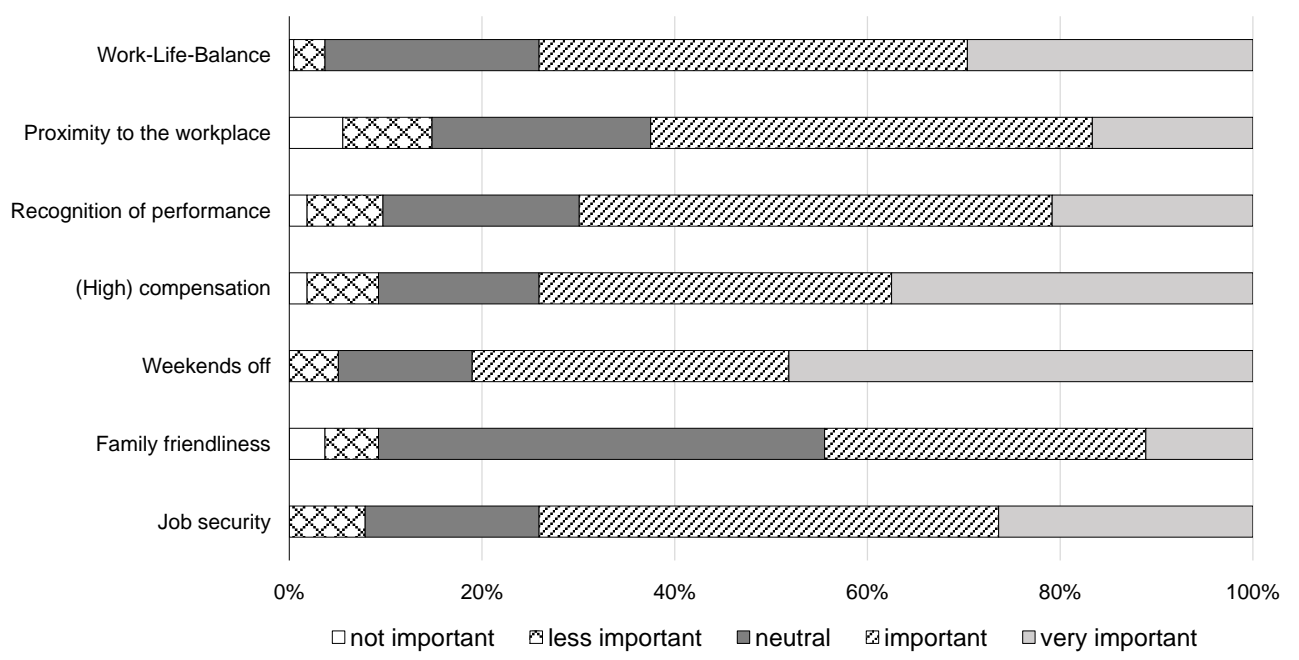

Figure 5. Existence needs preferences by Millenials.

is thus considered being the most important among the existential needs. This is a particularly controversial finding from the retail sector's perspective, since Saturdays usually yield the highest turnover in a week, ergo necessitating an increased need for personnel. Yet, Millenials have a claim to continuous further education. They want to learn and develop themselves on a frequent basis. A free weekend and good work-life balance would provide the frame necessary, which is, however, rather difficult to achieve in the retail sector than in other industries. Merely positions in the company headquarters might allow this. Moreover, contrary to expectations, above-average salary is seen as "very important" and "important", at ca. $37 \%$ in each of the categories. Yet, this result contradicts the statements of Expert B (2018) and Expert A (2018) which certify the Millenials to waive the money in favour of other factors. Consequently, there is no need for great consideration to terminate an occupation if the employer does not meet essential requirements. On the other hand, Holtbrügge and Kreppel (2015) evidenced high compensation to be the most important factor among German Millenials, closely followed by the factor job security. Findings by Steckl et al. (2019) also suggest compensationas less of a major driver of Millenials' employer selection in Germany (Steckl et al., 2019). Confirmingly, previous research have found compensation being of little significance in employer selection among this generation (Baum \& Kabst, 2013; Shell, 2015; Steckl et al., 2019). They rather prefer aspects as harmonious work climate and a fulfilling job, while older generations such as the baby boomers are more concerned with job security (Sommer et al., 2017). Besides, shortly behind rank two is a good work-life balance, which is considered "very important" by $30 \%$ and "important" by $44 \%$. In addition, $26 \%$ hold job security to be "very important" and $48 \%$ "important" regarding the future employer. Thus, job security is important to about half of the respondents. Other studies found this factor being the most crucial influencer when it comes to employer selection (Steckl et al., 2019). Recognition of one's own performance (21\% "very important" and $49 \%$ "important"), proximity to 
the workplace (17\% "very important" and $46 \%$ "important") and the family-friendliness of the company (11\% “very important" and 33\% "important") follow in conclusion. Proximity to the place of residence is considered "not important" by $5 \%$ and "less important" by $9 \%$. This may be evidence of the erratic nature of the Millenials, which was revealed in the interview with Expert A. In contrast, in a study conducted by Sommer et al. (2017) showed that proximity to the workplace is considered the most important attractiveness factor from a Millenial's angle.

\section{Relatedness Needs}

Figure 6 shows the extent to which the Millenials' relatedness needs are influenced by their employer choice.

At the relatedness level, the greatest importance is attached to a good working atmosphere (62\% "very important" and 25\% "important"). Only 3\% of those questioned consider the working climate "less or not important". Accordingly, a harmonious working environment is the most important factor in selecting an employer within the relatedness needs. Baum and Kabst (2013) reached a very same result, whereas in the study performed by Steckl et al. (2019), an harmonious working environment was found second important among German Millenials. Basically, this is achieved by a high degree of employee satisfaction through, inter alia, fair conduct of superiors, the offer of company events and a real feedback culture (also bottom-up). Following on from this, the transparency of a company influences the choice of employer as considered "very important" (45\%) and to "important" (31\%). An open company image is therefore the second most essential criterion among German Millenials and in line with Expert A, stating that transparency about the career path and the company structure is a pronounced demand of Generation Y. Yet, many German retailers provide merely partial insight into internal structures, such as details of key figures, management or ownership structure. This means that employers in the German retail sector are only marginally able to meet Gen Y's call for transparency. In

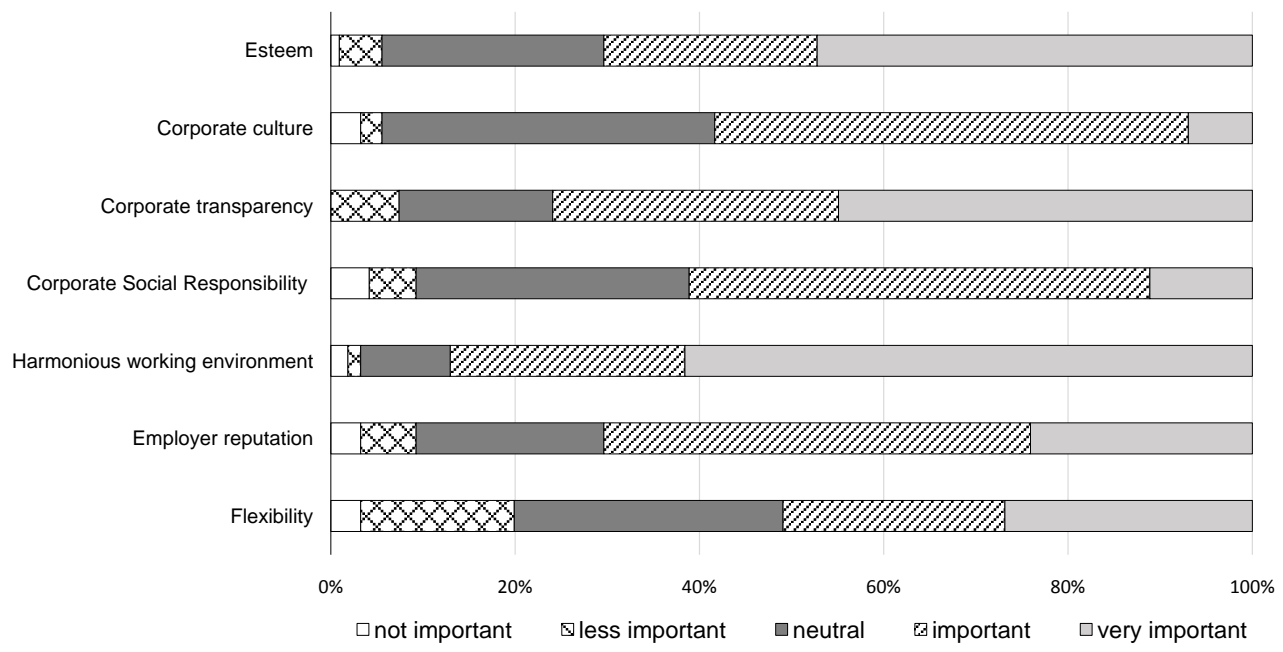

Figure 6. Relatedness needs preferences by Millenials. 
direct comparison, corporations such as VW, BMW Daimler or SAP offer complete transparency regarding corporate structure and balance sheet being appreciated by the Millenials. Nonetheless, this can be attributed to the legal requirement of being listed on the stock exchange. Furthermore, esteem, a soft factor, is believed as an "very important" (47\%) or "important" (23\%) factor in the choice of an employer. The demand for esteem is based primarily on the Millenials' desire to be able to contribute to the company with their work to make a difference. Besides, the reputation of an industry also plays a significant role in the search for an employer. Thus, $24 \%$ of the respondents hold this factor "very important" whereas $46 \%$ believe it is "important". Millenials assume that companies with a good reputation handle many things properly and are hence more likely capable of meeting their own needs as well. In addition, as the Gen Y is highly qualified and confident, they prefer an employer who shares these characteristics. The next rank is occupied by social commitment (11\% "very important" and 50\% "important"). Growing up in financially well-off families in the context of global crises awakens the desire for charity. The future employer should therefore make a positive contribution to society. Beyond that, corporate culture (7\% "very important" and 51\% "important") and flexible working time models (25\% "very important" and 24 "important") affiliate. Since $20 \%$ of the respondents see flexible working time models as having only a minor influence on the choice of employer, this criterion represents the clear conclusion of the relatedness needs.

\section{Growth Needs}

Figure 7 provides a summary of the growth needs of Generation Y.

The range of development opportunities has with $48 \%$ "very important" and $40 \%$ "important" a considerable influence on choosing an employer and therefore being the most important criterion in this category. Likewise, findings of Baum and Kabst (2013) in line with Franke (2000), further emphasize the significance of this factor within the German labor market. The second place is occupied

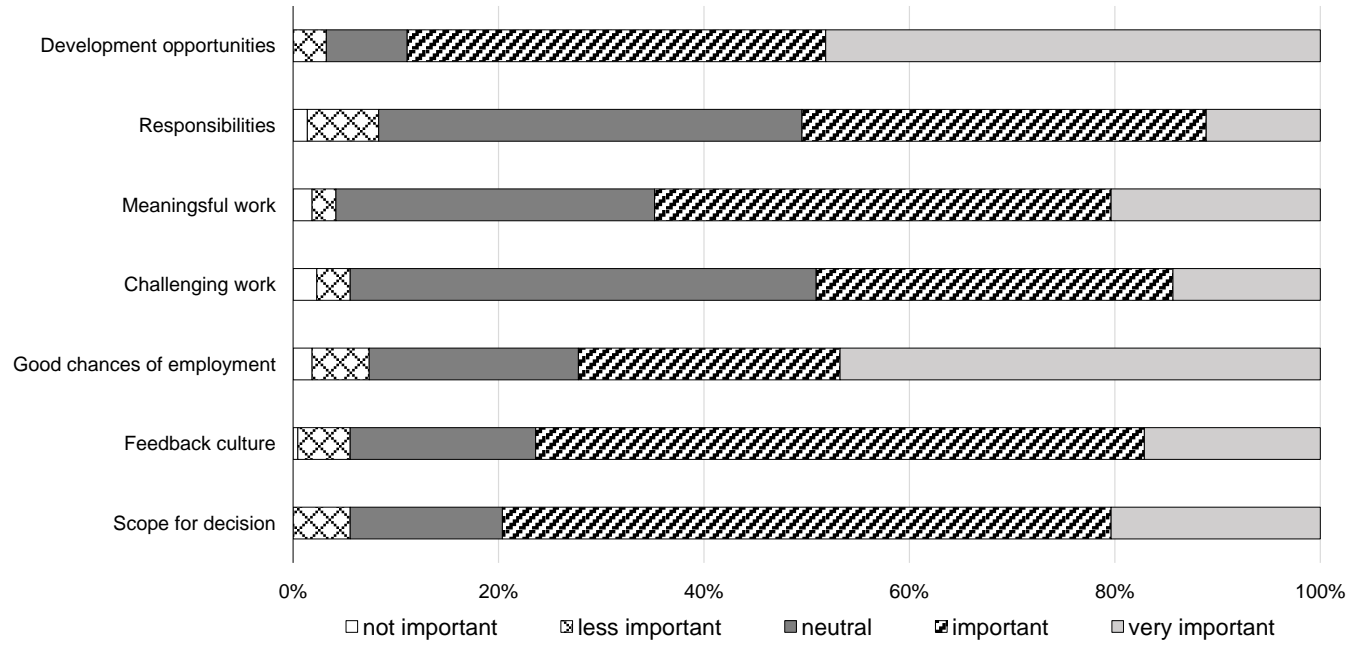

Figure 7. Growth needs preferences by Millenials. 
by scope of decision as rated as "important" and "very important" by $79 \%$ of the participants. This result is confirmed by Expert B (2018), asserting that only sufficient freedom of decision-making ultimately enables self-development potential. Demanding continuous feedback is also characteristic of Generation Y. For this reason, they believe (17\% "very important" and 59\% "important") that the presence of a lived corporate feedback culture strongly influences their decisions. Especially in today's rapidly evolving environment, Generation $\mathrm{Y}$ is longing for constant and above all immediate feedback. An instant assessment of their performance can be used to regularly identify potential for improvement and development. It is, therefore, hardly surprising that the corporate feedback culture is positioned in the top 3 of growth needs. Additionally, good chances of employment (46\% "very important" and 26\% "important") are also crucial basis of decision-making. This tendency has already been indicated by the high importance of job security among the existential needs. Job security and good chances of employment go hand in hand. These factors might gain even more gravitas due to the ongoing COVID-19 crisis. However, meaningfulness of work is also essential, since 65\% hold it "important" and "very important in their choice of employer. Millenials do not want to work for the sake of work and money solely, they rather need to get a deeper meaning out of it (Expert B, 2018). Finally, the assumption of responsibility (11\% "very important" and $39 \%$ "important") and the desire for challenge (14\% "very important" and 35\% "important") bear mention. Accordingly, companies must provide opportunities to allow for independent decisions albeit challenging.

In this category, it is striking that scarcely any of the criteria are considered to be of minor significance. All growth needs, with the exception of two, are classified as "important" and "very important" with at least $60 \%$. This indicates that Generation $\mathrm{Y}$ is positioned at the top level of Maslow's pyramid of needs, where the focus is on the extent of autonomy and self-realization. Consequently, relatedness and existential needs do not have the same weighting as growth needs. This, is also representative of the characterization of Generation $\mathrm{Y}$ since the growing up in political and economic stability, enables the Millenials to strive for self-realization and free development as three lowest layers have already been satisfied.

Although millennial preferences align with retailing, they do not prefer this industry as it is merely fourth popular among German Millenials according to this study. This might be attributable to the fact that Millenials are not aware of the benefits of retail employers, since, as the survey results indicate, no significant attractiveness factors are associated with retailing. Millenials think about retail from the customer's point of view and not from that of employees. The lack of knowledge about required attractiveness factors that are actually provided could be due to a deficiency in communication on the part of the retailers. IT or automotive companies are the most popular candidates for the Millenials, as they are already expected to pay high salaries, provide an innovative and varied work environment as well as flexible working hours. Such attributes are not 
ascribed to the retail sector, since no attempt has been made to recruit high potentials by means of effective target group-specific recruitment campaigns.

\subsection{ERG Theory Related to Retailing Experts' Assessment}

A practical analysis of the attractiveness factors embedded in the ERG theory by retail and Gen Y experts yielded the following result outlined in Table 4 in the form of a traffic light system. The red tinge implies the absence or limited presence of this factor among employers in the German retail industry.

As the majority of professions in retailing relates to jobs on the sales floor, there is often a lack of a proper work-life balance, because the weekend as a sales driver requires more personnel. Consequently, retailers often only grant their employees one off Saturday per month. In many cases the company and ownership structure is barely comprehensible owing to the lack of public transparency. Furthermore, the top management of leading German retailers is less media-present than, for instance, its industrial equivalents. This has a corresponding impact on the reputation of the retail sector as an appealing pool of employers. According to the experts A, B, C, D, E (2018), there is also frequently a shortage of a wide range of development opportunities from which employees can draw autonomously. In addition, in the vast majority of instances, feedback is only provided top-down rather than vice-versa, which would, yet, convey and enhance trust and esteem.

Nevertheless, as Table 3 illustrates, employers in the German retail sector possess most of the attributes demanded, contradicting a possible negative reputation of the industry and the assumptions of the survey participants. Accordingly, the German retail sector bears tremendous potential becoming the "sector of choice" for Millenials, given that existing attractiveness factors are adequately promoted and purposefully addressed.

Overall, the results imply a confirmation of the first hypothesis whereas the second hypothesis could be refuted. The retail industry is actually perceived as just less attractive, whereby unjustified as the survey data reveals. Employers in the retail industry provide a majority of the attractiveness factors required by the

Table 4. Attractiveness factors of generation Y (ERG theory).

\begin{tabular}{|c|c|c|}
\hline Existence Needs & Relatedness Needs & Growth Needs \\
\hline (High) compensation & Corporate culture & Good chances of employment \\
\hline Job security & $\begin{array}{l}\text { Harmonious working } \\
\text { environment }\end{array}$ & Development opportunities \\
\hline Work-Life-Balance & Employer reputation & Meaningful work \\
\hline Proximity to the workplace & Esteem & Scope for decisions \\
\hline Family friendliness & Flexibility & Feedback culture \\
\hline Free weekends & $\begin{array}{c}\text { Corporate Social } \\
\text { Responsibility (CSR) }\end{array}$ & Responsibilities \\
\hline Recognition of performance & Corporate transparency & Challenging work \\
\hline
\end{tabular}


Millenials. At this point, there is a need for communication on the part of employers to broadly present the given advantages to the Millenials in a targeted fashion in order to give rise to a more positive image of the existing working environment and conditions.

\section{Conclusion and Implications}

The aim of this paper was to identify the factors of employer attractiveness from a Millenials point of view in a retailing context. An additional validation of the results was carried out by means of qualitative industry expert interviews.

Today's market requirements are increasingly being altered by global megatrends. Demographic change and new social values are causing a shortage of skilled workers, so that the transformation from an employer market to an employee market has already been completed. Consequently, attractive positioning in the competitive environment is becoming an ever more important factor. Companies are forced to systematically recruit high potential employees in order to gain competitive edge. Yet, the Generation $\mathrm{Y}$ is placing entirely new demands on their employers. More than ever, companies have to meet these demands in order to attract and retain future high potentials. Employer branding has proven an effective instrument to achieve this endeavor.

\subsection{Theoretical Implications}

To the best of the author's knowledge, this research represents the first comprehensive survey on the assessment of the attractiveness of the German retail industry from the perspective of the Millenials, thus, the first identification of employer attractiveness factors and desired employers with regard to the German retail landscape.

Based on previous studies and expert interviews, the ERG theory has been extended and specified by essential factors relevant to the German retail sector. Future studies can use the model for further research in this area.

\subsection{Managerial Implications}

The insights gained may serve managers at retail companies to align their employer branding strategy as well as recruiting oriented corporate communications with the relevant target group, namely the Generation Y. Accordingly, internal processes might be adapted to the preferences of the Millenials to allow for the retention of the existing workforce by rendering the working environment more appealing. Conclusively, uncoordinated recruitment can be effectively transformed into targeted and efficient campaigns to counteract the shortage and loss of skilled and promising employees.

The extended ERG theory provides practitioners with an overview of the employer characteristics relevant to the German retail industry from the perspective of the Millenials. In addition, the survey results offer a relevance ranking of the attractiveness factors that are most preferred. Advertising budgets and HR cam- 
paigns can be targeted according to this list in order to attract and retain members of the Gen Y.

\subsection{Limitations and Future Research Directions}

The sample was limited to one school solely. In order to further increase the heterogeneity of the participants and thus the significance of the survey results, future research should increase the number of participants and additionally be conducted across various sectors and institutions.

Future researchers might investigate a wider population of Millenials when determining employer preferences and attractiveness characteristics. Furthermore, a comparison with the next generation employees, Gen Z, would be another research field that will increasingly come into focus over the coming years.

Besides, the selection of attractiveness factors could also be expanded in number to also take into account peripheral effects.

\section{Conflicts of Interest}

The authors declare no conflicts of interest regarding the publication of this paper.

\section{References}

Alderfer, C. (1969). An Empirical Test of a New Theory of Human Needs. Organizational Behavior and Human Performance, 4, 142-175. https://doi.org/10.1016/0030-5073(69)90004-X

Ambler, T., \& Barrow, S. (1996). The Employer Brand. Journal of Brand Management, 4, 185-206. https://doi.org/10.1057/bm.1996.42

Andreassen, T. W., \& Lanseng, E. J. (2010). Service Differentiation: A Self-Image Congruency Perspective on Brand Building in the Labor Market. Journal of Service Management, 21, 212-236. https://doi.org/10.1108/09564231011039295

Bahner, J., \& Eisele, D. (2004). Das Arbeitgeberimage im Mittelpunkt-Campus Recruiting. In Universität Stuttgart (Ed.), Jahrbuch Wechselwirkungen (pp. 3-20). Stuttgart: Universität Stuttgart.

Bartosik-Purgat, M., \& Jankowska, B. (2017). The Use of Social Networking Sites in Job Related Activities: A Cross-Cultural Comparison. Entrepreneurial Business and Economics Review, 5, 177-193. https://doi.org/10.15678/EBER.2017.050210

Baum, M., \& Kabst, R. (2013). How to Attract Applicants in the Atlantic versus the Asia-Pacific Region? A Cross-National Analysis on China, India, Germany, and Hungary. Journal of World Business, 48, 175-185. https://doi.org/10.1016/j.jwb.2012.07.002

Berthon, P., Ewing, M., \& Hah, L. L. (2005). Captivating Company: Dimensions of Attractiveness in Employer Branding. International Journal of Advertising, 24, 151-172.

https://doi.org/10.1080/02650487.2005.11072912

Christiaans, L. (2013). International Employer Brand Management: A Multilevel Analysis and Segmentation of Students' Preferences. Wiesbaden: Springer Gabler. https://doi.org/10.1007/978-3-658-00456-9

Cisik, A. (2015). Arbeitgeberattraktivität zwischen Anspruch und Wirklichkeit. Eine em- 
pirische Studie. Management Summary.

http://www.cisikconsulting.de/wp-content/uloads/2015/10/Cisik Arbeitgeberattraktivit \%C3\%A4t-zwischen-Anspruch-und-Wirklichkeit Management-Summary 170915.pdf

Destatis (2019). Statistisches Bundesamt Deutschland-GENESIS-Online: Die Datenbank des Statistischen Bundesamtes.

https://www-genesis.destatis.de/genesis/online

Destatis (2020). Eckzahlen Zum Arbeitsmarkt, Deutschland.

https://www.destatis.de/DE/Themen/Arbeit/Arbeitsmarkt/Erwerbstaetigkeit/Tabellen/ eckwerttabelle.html;jsessionid=18DB657C9F128E1F362DBB229B1939B2.internet8711

Eger, L., Mičík, M., Gangur, M., \& Řehoř, P. (2019). Employer Branding: Exploring Attractiveness Dimensions in a Multicultural Context. Technological and Economic Development of Economy, 25, 519-541. https://doi.org/10.3846/tede.2019.9387

Embrace (2015). Embrace Studie-Karriere trifft Sinn. https://www.saatkorn.com/wordpress/wp-content/uploads/delightful-downloads/2015/ 12/Epaper Karriere trifft Sinn.pdf?utm source=wysija\&utm medium=email\&utm $c$ ampaign=Download-Studie-KtS

Flick, U. (2014). An Introduction to Qualitative Research. Los Angeles, CA: SAGE Publications.

Frank, F. D., Finnegan, R. P., \& Taylor, C. R. (2004). The Race for Talent: Retaining and Engaging Workers in the 21st Century. Human Resource Planning, 27, 12-25.

Franke, N. (2000). Personalmarketing zur Gewinnung von betriebswirtschaftlichem Führungsnachwuchs. Zur Positionierung von Unternehmen in studentischen Zielgruppen. Marketing ZFP Zeitschrift für Forschung und Praxis, 22, 75-92. https://doi.org/10.15358/0344-1369-2000-1-75

Geighardt-Knollmann, C. (2011). DGFP Studie: Megatrends und HR Trends. https://www.dgfp.de/hr-wiki/Employer Branding.pdf

Graham, B. Z., \& Cascio, W. F. (2018). The Employer-Branding Journey: Its Relationship with Crosscultural Branding, Brand Reputation, and Brand Repair. Management Research-The Journal of the Iberoamerican Academy of Management, 16, 363-379. https://doi.org/10.1108/MRJIAM-09-2017-0779

Graue, C. (2015). Special Issue: Research Methodology-Qualitative Data Analysis. International Journal of Sales, Retailing and Marketing, 9, 5-14.

Hackman, J., \& Lawler, E. (1971). Employee Reactions to Job Characteristics. Journal of Applied Psychology, 55, 259-286. https://doi.org/10.1037/h0031152

Hall, P. A., \& Soskice, D. (2001). Varieties of Capitalism. Oxford: Oxford University Press. https://doi.org/10.1093/0199247757.001.0001

HDE (2019). Beschäftigungsstruktur im Einzelhandel. https://einzelhandel.de/beschaeftigungsstruktur

Holste, J. H. (2012). Arbeitgeberattraktivität im demographischen Wandel: Eine multidimensionale Betrachtung. Wiesbaden: Springer. https://doi.org/10.1007/978-3-8349-4442-9

Holtbrügge, D., \& Kreppel, H. (2015). Employer Attractiveness of Chinese, Indian and Russian Firms in Germany: Signaling Effects of HR Practices. Corporate Reputation Review, 18, 223-242. https://doi.org/10.1057/crr.2015.12

Ifo (2018). Beschäftigungsentwicklung im Handel: Besteht ein Arbeitskräftemangel in der Branche?

https://www.ifo.de/DocDL/sd-2018-09-rumscheidt-arbeitskraeftemangel-handel-201805-09.pdf 
Kanfer, R., Frese, M., \& Johnson, R. E. (2017). Motivation Related to Work: A Century of Progress. Journal of Applied Psychology, 102, 338-355.

https://doi.org/10.1037/apl0000133

Kim, H. J., Knight, D. K., \& Crutsinger, C. (2009). Generation Y Employees' Retail Work Experience: The Mediating Effect of Job Characteristics. Journal of Business Research, 62, 548-556. https://doi.org/10.1016/j.jbusres.2008.06.014

Klaffke, M. (2014). Erfolgsfaktor Generationen-Management-Handlungsansätze für das Personalmanagement. In M. Klaffke (Ed.), Generationen-Management (pp. 3-25). Wiesbaden: Gabler. https://doi.org/10.1007/978-3-658-02325-6 1

Köcher, R., Sommer, M., \& Hurrelmann, K. (2015). Die McDonald's Ausbildungsstudie 2015: Entschlossen unentschlossen. Azubis im Land der (zu vielen) Möglichkeiten. https://www.ifd-allensbach.de/fileadmin/IfD/sonstige_pdfs/McDonald_s Ausbildungss tudie 2015.pdf

Künzel, H. (2013). Erfolgsfaktor Employer Branding: Mitarbeiter binden und die Gen $Y$ gewinnen. Berlin: Springer Gabler. https://doi.org/10.1007/978-3-642-40535-8

Kupperschmidt, B. R. (2000). Multigeneration Employees: Strategies for Effective Management. Health Care Management, 19, 65-76. https://doi.org/10.1097/00126450-200019010-00011

Lee, C.-C., Kao, R.-H., \& Lin, C.-J. (2018). A Study on the Factors to Measure Employer Brand: The Case of Undergraduate Senior Students. Chinese Management Studies, 12, 812-832. https://doi.org/10.1108/CMS-04-2017-0092

Lindgren, E., \& Skarped, M. (2008). Employer Attractiveness. A Quantitative Survey of Preferences among Swedish Civil Engineering Students Regarding Future Employers. Bachelor Thesis, Uppsala: Uppsala University, Department of Business Studies.

Malhotra, N. K. (2010). Marketing Research: An Applied Orientation. Sixth Edition, Global Edition. Boston Amsterdam Dubai: Pearson. Journal of Service Research, 7, 343-359.

Moroko, L., \& Uncles, M. (2008). Characteristics of Successful Employer Brands. Journal of Brand Management, 16, 160-175. https://doi.org/10.1057/bm.2008.4

Parment, A. (2013). Die Generation Y: Mitarbeiter der Zukunft motivieren, integrieren, führen. Wiesbaden: Gabler Verlag.

Ruthus, J. (2013). Employer of Choice der Generation Y: Herausforderungen und Erfolgsfaktoren zur Steigerung der Arbeitgeberattraktivität. Zugl.: Riedlingen, Fernhochsch., Masterthesis, Wiesbaden: Springer Gabler.

https://doi.org/10.1007/978-3-658-04734-4

Ruthus, J. (2014). Arbeitgeberattraktivität aus Sicht der Generation Y: Handlungsempfehlungen für das Human Resources Management. Berlin: Springer Gabler. https://doi.org/10.1007/978-3-658-07918-5

Sengupta, A., Bamel, U., \& Singh, P. (2015). Value Proposition Framework: Implications for Employer Branding. Decision, 42, 307-323.

https://doi.org/10.1007/s40622-015-0097-x

Sharma, R., \& Prasad, A. (2018). Employer Brand and Its Unexplored Impact on Intent to Join. International Journal of Organizational Analysis, 26, 536-566.

https://doi.org/10.1108/IJOA-11-2017-1280

Shell (2019). Shell Jugendstudie 2019.

https://www.shell.de/ueber-uns/shell-jugendstudie.html

Sommer, L. P., Heidenreich, S., \& Handrich, M. (2017). War for Talents-How Perceived 
Organizational Innovativeness Affects Employer Attractiveness. R\&D Management, 47, 299-310. https://doi.org/10.1111/radm.12230

Steckl, M., Simshäuser, U., \& Niederberger, M. (2019). Arbeitgeberattraktivität aus Sicht der Generation Z. Prävention und Gesundheitsförderung, 14, 212-217. https://doi.org/10.1007/s11553-019-00703-w

Stotz, W., \& Wedel, A. (2009). Employer Branding: Mit Strategie zum bevorzugten Arbeitgeber. München: De Gruyter. https://doi.org/10.1524/9783486592481

Stotz, W., \& Wedel, A. (2013). Employer Branding: Mit Strategie zum bevorzugten Arbeitgeber. 2. Aufl., München: De Gruyter. https://doi.org/10.1524/9783486754377

Tanwar, K., \& Prasad, A. (2016). The Effect of Employer Brand Dimensions on Job Satisfaction: Gender as a Moderator. Management Decision, 54, 854-886. https://doi.org/10.1108/MD-08-2015-0343

Tepper, B., Dimotakis, N., Lambert, L., Koopman, J., Matta, F., Man Park, H., \& Goo, W. (2018). Examining Follower Responses to Transformational Leadership from a Dynamic, Person-Environment Fit Perspective. Academy of Management Journal, 61, 1343-1368. https://doi.org/10.5465/amj.2014.0163

Theurer, C. P., Tumasjan, A., Welpe, I. M., \& Lievens, F. (2018). Employer Branding: A Brand Equity-Based Literature Review and Research Agenda. International Journal of Management Reviews, 20, 155-179. https://doi.org/10.1111/ijmr.12121

Trendence (2019). Das fordern young professionals. https://www.trendence.com/reports

von Walter, B., \& Kremmel, D. (2016). Employer Brand Management. Arbeitgebermarken aufbauen und steuern. Berlin: Springer Gabler. https://doi.org/10.1007/978-3-658-06938-4

Winter, S. (2000). Quantitative vs. Qualitative Methoden. http://nosnos.synology.me/MethodenlisteUniKarlsruhe/imihome.imi.uni-karlsruhe.de/ nquantitative vs qualitative methoden b.html

Wolf, G. (2014). Employer Branding. Dashöfer.

Wolter, U. (2020). "Stern” und Statista ermitteln beste Arbeitgeber Deutschlands. https://www.personalwirtschaft.de/recruiting/employer-branding/artikel/stern-und-sta tista-ermitteln-deutschlands-beste-aarbeitgeber.html

Wong, M., Gardiner, E., Lang, W., \& Coulon, L. (2008). Generational Differences in Personality and Motivation. Do They Exist and What Are the Implications for the Workplace? Journal of Managerial Psychology, 23, 878-890.

https://doi.org/10.1108/02683940810904376

Zhu, F., Wang, Z., Yu, Q., Hu, T., Wen, Y., \& Liu, Y. (2014). Reconsidering the Dimensionality and Measurement of Employer Brand in the Chinese Context. Social Behavior and Personality, 42, 933-948. https://doi.org/10.2224/sbp.2014.42.6.933 